\title{
Measuring knowledge and practice in relation to breast cancer screening in mothers in Pakistan
}

\author{
Sharmeen Amin*1, Zafeer Ahmed Yazdani ${ }^{1}$, Ankush $\mathrm{Jha}^{2}$, Deepika Sriram ${ }^{3}$, Hinozia Merchant ${ }^{4}$, Naveen Reddy Parva ${ }^{3}$, \\ Artur Mirzabekian ${ }^{5}$, Joana Kendra Pascal ${ }^{6}$, Sehrish Sikandar ${ }^{1}$, Bryan E Xin Tan ${ }^{7}$, Zhi Tian Chen ${ }^{7}$, Aakash Kumar ${ }^{1}$, \\ Faris Baig ${ }^{1}$, Muhammad Baseem Sheikh ${ }^{1}$, Zia Imtiaz ${ }^{8}$ \\ 1 Jinnah Sind Medical University, Karachi, Pakistan \\ ${ }^{2}$ Smolensk State Medical Academy, Smolensk, Russia \\ ${ }^{3}$ Mamata Medical College, Telangana, India \\ ${ }^{4}$ Dow Medical College, Karachi, Pakistan \\ ${ }^{5}$ Stavropol State Medical University, Stavropol, Russia \\ ${ }^{6}$ Atlantic University School of Medicine, Saint Lucia \\ ${ }^{7}$ I.M. Sechenov First Moscow State Medical University, Moscow, Russia \\ ${ }^{8}$ Ziauddin Medical College, Karachi, Pakistan
}

Received: May 18, 2015

DOI: $10.5430 /$ jha.v6n2p81
Accepted: September 17, 2016 Online Published: March 15, 2017

URL: https://doi.org/10.5430/jha.v6n2p81

\begin{abstract}
Background: Breast cancer is a major health burden mainly in the developed countries but its rates are also increasing in the developing countries. With such increasing rates of breast cancer it is imperative that the general population is aware of its risk factors, early screening methods and the preventive measures that can be undertaken before its development.

Objective: To assess the awareness of breast-self-examination (BSE) \& screening among the mothers belonging to different socioeconomic groups in Karachi, Pakistan. To assess the awareness of breast lump \& its relation with breast cancer in mothers. Methods: This is a cross sectional research study constituting on a sample size of 284 people. The data was collected using a self administered questionnaire which was designed after detailed literature review. The date was collected from all 5 districts of Karachi, Pakistan. The duration of data collection was from April 2013 to November 2013. The data was analyzed using spss 19 with a $95 \%$ confidence interval and a $5 \%$ margin of error. A $p$-value of .05 or less was considered significant.

Results: The results showed that most of the women (81\%) have sufficient general knowledge about breast cancer and its outcomes but the awareness regarding the risk factors was limited. Only $38 \%$ were aware that old age is a risk factor, $34.9 \%$ knew that null parity is a risk factor while $57.7 \%$ believed that trauma to the breast, for example child hitting the breast, cause breast disease. The women were only partially aware of the screening methods available, only $53.2 \%$ of women knew how to self-examine their breast and $69 \%$ of them were not aware of the fact that mammography is the basic screening procedure. Results are similar for knowledge about signs and symptoms and only $46.8 \%$ were aware that bloody discharge and inward retraction of nipple may be due to breast cancer. Despite the limited current awareness about the breast diseases most women $(82.4 \%)$ showed interest in learning more information about breast diseases and how might they be prevented.

Conclusions: The study concluded that though the mothers were aware of breast cancer they still require sufficient knowledge regarding its risks, methods of screening and means to prevent it. In accordance with this need more initiatives should be undertaken to spread more awareness regarding this through media or other useful sources. But increasing awareness alone cannot deliver the desired results and there is a parallel need to increase the facilities and to make them accessible for all. Steps
\end{abstract}

\footnotetext{
*Correspondence: Sharmeen Amin; Email: sharmeenamin26@gmail.com; Address: Jinnah Sind Medical University, Formerly Sind Medical College, Dow University of Health Sciences, 408 A1, Billy’s Garden Ab ul Hassan Isphahani Road, Karachi, Pakistan.
}

Published by Sciedu Press 
should also be undertaken to educate the women about their misconceptions regarding breast cancer and to make them free from unnecessary barriers as many women do not seek clinical advice due to these barriers.

Key Words: Assess, Awareness, Attitude, Breast cancer, Screening, Mothers

\section{INTRODUCTION}

Prevention is better than cure especially when the disease is as deadly as breast cancer. ${ }^{[1]}$ The first step in an effort to prevent breast cancer is to provide knowledge about the disease. ${ }^{[2]}$ It is important for the general population to be educated about the etiology, pathogeneses, clinical presentation, screening methods, treatment and management of breast cancer. The greater the understanding of what breast cancer is and awareness regarding breast-self-examination (BSE), the earlier the detection and higher the chances of survival. ${ }^{[3]}$ Hence, raising breast cancer awareness will proportionately reduce the occurrence and mortality rate due to this life threatening disease.

Breast cancer is the second most leading cause of death among women worldwide. ${ }^{[1]}$ This high mortality rate is mainly due to late stage diagnoses, since patients usually present at an advanced stage because of lack of awareness and a non-existent breast cancer screening program in some underdeveloped parts of the world, especially in the low socio economic regions. ${ }^{[3]}$ In low socio economic countries the incidence has significantly increased during the last few years. ${ }^{[4]}$ This rise is due to a combination of deficiency of knowledge and scarce available facilities for women to be examined at. ${ }^{[3]}$ Therefore, it is important for focus to be shifted towards awareness and screening, rather than the treatment of this disease because early detection increases the survival rate of patients. ${ }^{[5]}$

A lot of researches have been conducted all around the world to determine the level of awareness and screening benefits among women. In Korean American women, the frequency of breast cancer screening practices, such as clinical breast exams (CBE) and Mammography, is below their national objectives. ${ }^{[6]}$ Whenever there are reduced chances of adequate screening, either due to lack of awareness or the accessibility to well equipped centers, the chances of early detection of breast cancer become less and with the decreasing early detection the chances of a worse outcome increase significantly. The risk factors identified by a research in Southern India include family history of breast cancer and breast feeding less than 2 years. The other risk factors are old age, null parity and use of contraceptives. ${ }^{[1]}$

The practice of breast self-examination among women in Malaysia is significantly influenced by their knowledge of breast cancer, their knowledge that early detection of breast cancer improves the survival and by their awareness of the benefits of BSE. ${ }^{[7]}$ This clearly depicts how important providing knowledge and raising awareness can be in the detection and prevention of this deadly cancer from creating a very poor prognosis and claiming thousands of lives worldwide annually.

In some regions of the world, namely the Asian subcontinent, the reason for not seeking medical care for breast pathologies is mostly dependent on the cultural norms and beliefs. Due to which despite having sufficient knowledge it becomes difficult for some women to seek medical care and screening for breast pathologies. ${ }^{[7]}$ For instance, despite the impact of education and awareness of BSE among female college students in India, the same girls are not able to undergo primary prevention for such breast diseases which may result in a worsened outcome. ${ }^{[3]}$

In accordance with a study based in Africa, all the participants of the study agreed that they have been unable to seek screening facilities for breast cancer either due to lack of awareness or lack of facilities in their area of residence. ${ }^{[8]}$ In Pakistan, the problem stems from the same root. According to a study conducted in Lahore, Pakistan, the women were not familiar with the basic screening methods especially the methods of BSE ${ }^{[9]}$ For this reason, efforts should be aimed at early detection because this can reduce the stage at diagnosis, potentially improving the odds of survival and cure, and enabling simpler and more cost-effective treatment. ${ }^{[10]}$

The risk of breast cancer is associated with pregnancy and different habits of breast feeding. Therefore, it is imperative that the mothers in the society are especially well aware of the risk of development of breast cancer, its early detection methods and of the centers that can provide them with clinical benefit if they happen to develop signs of breast disease. ${ }^{[11]}$ There is a crucial need for us to raise awareness about breast cancer as a disease and its screening methods so as to detect it earlier and prevent the life threatening consequences. ${ }^{[2,12,13]}$ The initial need is to conduct a research to evaluate how much knowledge mothers already have in Karach about breast cancer and to educate them regarding this cancer accordingly.

Therefore, the purpose of this study is to assess the level of awareness of breast cancer, its risks and screening procedures 
in order to estimate the level of awareness programs that need to be conducted and the screening facilities established in the city to provide a better prognosis for this disease.

\section{METHOD}

This is a cross sectional study. The study was conducted in Karachi, Pakistan and the data was collected from all 5 districts of Karachi. A questionnaire was designed specifically for the study after careful literature review. The questionnaire constituted on sections on general awareness among the women about breast cancer, their knowledge about the risks of breast cancer and awareness about the basic screening methods and investigations for early detection of breast cancer. The questions included were broadly of two types, one type of questions asked the patients to respond in a simple yes or no and if the patient answered yes to the BSE and mammography questions it was further determined how frequently do the conduct these examinations. After formal ethical approval from the department of community medicine in Jinnah Sindh Medical University the data was collected by interviewing the study participants.

The study was conducted from April 2013 to November 2013 during which the investigators collected the data. The women included in the study as study participants had either conceived a child in the past or were currently pregnant at the time of enrollment into the study. The target age group was 20 years to 60 years old who belong to the low socioeconomic group as determined by the interview. Women who has either never conceived a child in the past or were not currently pregnant at the time of study and those belonging to mid or high socioeconomic status were not included in the study. And the women with ages below 20 years and above 60 years were also not included.

A total of 284 samples were collected by the authors of this study. The data was analyzed using spss 19 and a confidence internal was set for $95 \%$ with a margin or error being set as $5 \%$ and $p$-value of .05 was considered statistically significant.

\section{RESUltS}

The results demonstrated that the knowledge regarding breast cancer is fairly limited among the mothers belonging to low socioeconomic group of Karachi's population. Although most ( $81 \%$ out of 284) were aware that women can develop breast disease (see Figure 1), there is a lack of awareness regarding risk factors. Only $38 \%$ were aware that old age is a risk factor, $34.9 \%$ knew that null parity is a risk factor while $57.7 \%$ believed that trauma to the breast to cause breast disease. There is not enough awareness regarding methods of screening, only $53.2 \%$ of women knew how to self examine their breast. $69 \%$ were not aware of the fact that mammogra- phy is now the basic screening test for breast cancer. Figure 2 demonstrates the results regarding the awareness about and performance of the screening tests among the study participants. Results are similar for knowledge about signs and symptoms and only $46.8 \%$ were aware that bloody discharge and inward retraction of nipple may be due to breast cancer. The frequency of responses received by the research subjects has been summarized in Table 1 .

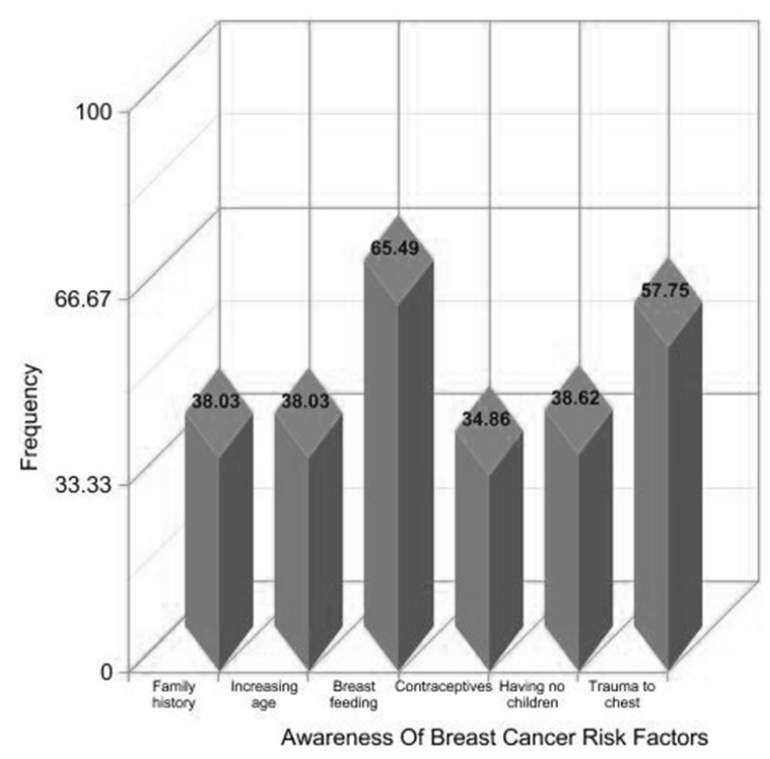

Figure 1. Frequency of awareness about breast lump risk factors

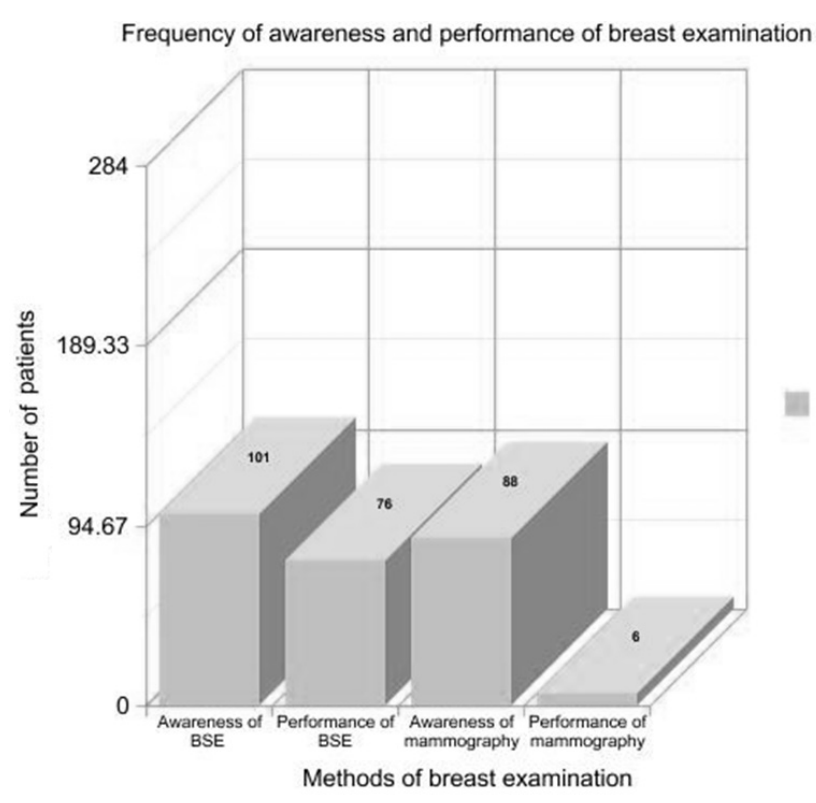

Figure 2. Frequency of the awareness and actual performance of the screening methods (BSE and mammography) for breast cancer 
Table 1. frequencies and chi square values for knowledge and awareness of mothers about breast cancer, its risk and screening methods

\begin{tabular}{|c|c|c|c|c|}
\hline Questions Asked & Yes $(\%)$ & No $(\%)$ & Chi squ & $p$-value \\
\hline - Women can develop lump in their breast? & 81 & 19 & 36.801 & $<.001$ \\
\hline - Do you know what is breast self-examination? & 35.6 & 64.4 & 36.801 & $<.001$ \\
\hline - Have you ever examined your breast? & 27.1 & 72.9 & 24.803 & $<.001$ \\
\hline - Mammography is the basic screening procedure for breast lump? & 31 & 69 & 23.208 & $<.001$ \\
\hline $\begin{array}{l}\text { - Do you know difference between both breast size and shape is related to } \\
\text { breast cancer? }\end{array}$ & 46.5 & 53.5 & 11.323 & .001 \\
\hline $\begin{array}{l}\text { - Do you know that inward retraction of nipple and bloody discharge is } \\
\text { related to breast Cancer? }\end{array}$ & 46.8 & 53.2 & 16.217 & $<.001$ \\
\hline - Do you know breast cancer if detected earlier can be treated? & 81.7 & 18.3 & 26.286 & $<.001$ \\
\hline - Do you know breast cancer is a life threatening disease? & 86.3 & 13.7 & 30.569 & $<.001$ \\
\hline - Do you want to get information about breast disease? & 82.4 & 17.6 & 3.182 & .002 \\
\hline - Would you convey any knowledge regarding breast disease to other? & 85.6 & 14.4 & 15.683 & $<.001$ \\
\hline
\end{tabular}

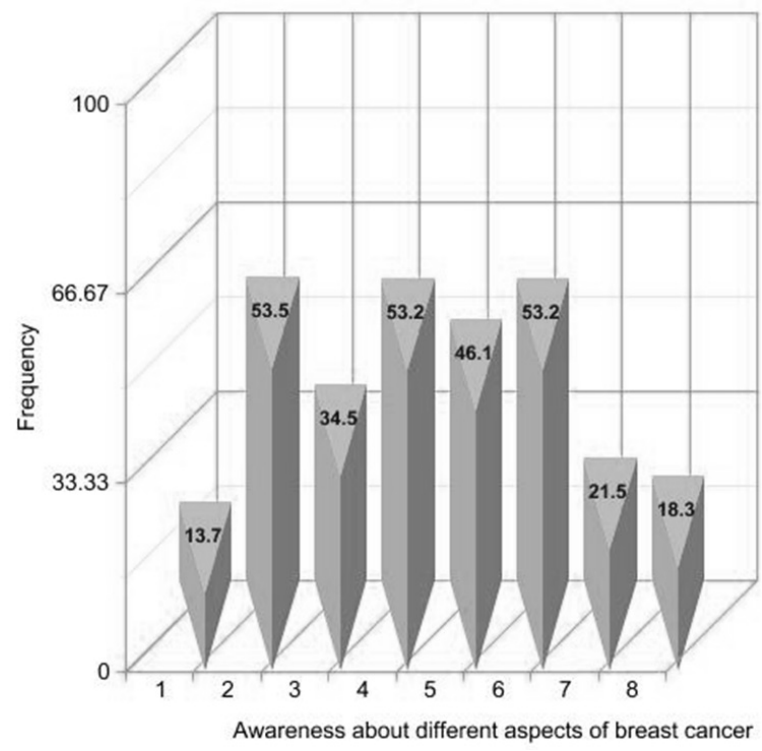

Figure 3. Frequencies of awareness about the major information regarding breast cancer

(Legends on $x$-axis:

1: Aware that breast cancer is life threatening;

2: Aware that breast cancer is life threatening;

3: Aware that breast cancer is preventable;

4: Aware that nipple discharge is associated with breast cancer;

5: Aware that armpit hump is related with breast cancer;

6: Aware that nipple retraction is associated with breast cancer;

7: Aware that breast hump can evolve into breast cancer;

8: Aware that breast cancer detected early can be treated)

Figure 3 highlights the major lack in awareness regarding breast cancer. The study also determined that $14.7 \%$ of the women were afraid to seek medical attention due to the fear of having the cancer itself. $20.1 \%$ of women confided that they are unable to seek medical care for breast related problems due to lack of financial support.
The data was analyzed using chi square and the results are presented in the Table 1. The study determined that the study participants had sufficient knowledge about the existence of breast cancer as a health hazard but the participants did not have sufficient knowledge regarding the risk factors, signs and symptoms and the basic screening methods, BSE and mammography, used in the screening of breast cancer.

\section{Discussion}

The study has been carried out to assess the level of awareness regarding breast cancer, its screening and its practices among the mothers of Karachi, Pakistan. The study determined that the study participants had sufficient knowledge about the existence of breast cancer and most of the study participants were also aware about at least a few of the risk factors leading to breast cancer development. The participants however lacked sufficient information about many risk factors including the relation of breast cancer with breast feeding practices, the relation between trauma to the breast and breast cancer and the relation of increasing age and positive family history with the development of breast cancer. ${ }^{[14]}$ The study participants though had sufficient knowledge about BSE the actual practice of BSE was not sufficient. Also, the study participants did not have sufficient awareness regarding mammography as the basic screening tool for breast cancer screening.

Surprisingly, majority $(81 \%)$ had heard something about breast cancer and this level of awareness is same as in western population as a study on Irish population shows the similar results ${ }^{[15]}$ which implies that there is sufficient awareness about the existence of breast cancer in this region of the world which is even comparative to that of the western world.

It is of prime importance that women should be aware of the 
fact that even if they have only a single risk factor they are at increased risk for the development of breast cancer and hence should have earlier screening for it. Studies have been done to assess the level of awareness about breast cancer risk factors among Pakistani women. According to a cross- sectional study carried out in a tertiary care hospital in Lahore, only $35 \%$ of the research participants were aware of one or two major risk factors while the remaining were not aware of any, ${ }^{[9]}$ this calls for much better awareness programs and patient education about the risk factors of breast cancer. The study conducted here shows that there is an increased level of awareness about relationship of breastfeeding with the development of breast cancer in mothers of Karachi, as only $34.5 \%$ of them believed that there is no relationship between breastfeeding practices and the risk of breast cancer indicating that there is sufficient information and knowledge among women of childbearing age about the risks and benefits of breast feeding. On the other hand the results were not satisfying concerning other risk factors and only $38 \%$ of mothers perceived increased age and family history as risk factors indicating the need for better awareness programs regarding these risk factors. Null parity was considered to be a risk factor by $36.6 \%$ of mothers and $34.9 \%$ believed that contraceptives can increase risk of breast cancer, whereas $57.7 \%$ of mothers had a wrong perception that trauma to the breast including a child hitting the breast is also a risk factor for breast cancer. ${ }^{[16]}$

A study among Malaysian women shows that $78.4 \%$ of the participants have heard about $\mathrm{BSE},{ }^{[7]}$ but the study done on mothers of Karachi shows that only $35.6 \%$ of them have heard about BSE and among those who had some knowledge the source of awareness was, Media, family, mother and child health center and awareness campaigns in $13.7 \%$, $7.7 \%, 7.4 \%$ and $6.7 \%$ of them respectively, this indicates that better public educational and awareness programs should be brought into play in methods that are more assessable to the population at large. Comparing the same couple of researches we find out that $47.2 \%$ of Malaysian women were examining their breast on monthly basis ${ }^{[7]}$ and among mothers of Karachi only $2.5 \%$ were examining their breast on daily basis, $5.3 \%$ on monthly basis and $19.4 \%$ occasionally, signifying the need for more frequent BSE.

Another study on Korean American women shows that 67\% of women had CBE at least once in their life6 but our study shows that only $10.9 \%$ mothers of the city ever had breast examination by a doctor which signifies the need for more efficient physical examination protocols by the physicians which take in light the lesser awareness of this socio-economic group about the risks of development of breast cancer and also the importance of early diagnosis via routine BSE, ex- amination by a physician and mammography. ${ }^{[17]}$

A reason for not getting proper medical attention on right time can be a fear of being diagnosed with the disease itself. ${ }^{[18]}$ A study in Jordan suggested that fear of being diagnosed as having breast cancer is one of the main reason for it ${ }^{[19]}$ but the results of our study have shown that only $14.4 \%$ of the women were afraid to seek medical care due to the fear of disease itself indicating that the fear of the disease in itself might be leading the patients to avoid seeking timely medical help. This signifies the importance of patient education about the better outcomes with early diagnoses and efficient management in a timely manner. ${ }^{[20,21]}$

One of the reasons for not getting a breast screen done as a preventive measure can be one of the many boundaries implemented by the low socioeconomic societies. This important factor has been highlighted by a research carried out in Turkey which identified that women in some areas of Turkey had been reluctant to seek medical care due to their lower economic and cultural beliefs. ${ }^{[2]}$ Also being an underdeveloped country, $20.1 \%$ the women in this study agreed to not have been able to get a CBE due to its costs.

The same study of turkey shows that shyness/embarrassment was the reason for which 5.0\% of the women were not having CBE. ${ }^{[22]}$ This ratio is much higher among the women enrolled in this study as $40.1 \%$ of them feel embarrassed on breast examination even by a female doctor. This calls for the physicians to build a better repo with the patients and educate them about the high need of breast evaluation. The clinic atmosphere should also be welcoming so that the patients seek medical care without being embarrassed or shy. Other expected barriers were determined to be lack of time and religious issues but the study shows that most (68\%) of the mothers were ready to take time out of their routine and only $12 \%$ of them were avoiding clinical breast examination due to religious issues. Another important and promising fact brought to light by the study is that $75.4 \%$ of the women in the study were positive that their families will allow them to get a breast examination done which is a very welcoming finding considering that the family's support is very important to deal with situations such as cancer especially breast cancer which can be very difficult of the patient.

About the last but the most important part of breast cancer screening, the study shows that only $31 \%$ of the mothers of Karachi know that Mammography is the basic screening procedure and this proportion is very close to that of Nigerian women in accordance with a study that showed that $32.8 \%$ of them had this knowledge, ${ }^{[23]}$ this indicates the very imminent need to organize awareness programs for the women to be aware of the importance of mammography as the screening 
test for breast cancer.

It is imperative for an earlier diagnosis and timely management of breast cancer that women should be aware about the clinical symptoms which might be a result of breast cancer. A study conducted at a tertiary care hospital in Lahore, Pakistan showed that $65 \%$ of the women who participated in the study were aware of at least one symptom of breast cancer. ${ }^{[9]}$ Whereas the mothers of Karachi have variable level of awareness about different signs and symptoms as the study shows that $78.5 \%$ of them know that breast lump can be due to breast cancer while around $46 \%$ were aware that bloody discharge, inward retraction of nipple and difference of size and shape of the breast are the signs and symptoms of breast cancer. These numbers though indicate somewhat awareness about the signs and symptoms of breast cancer but are not adequate enough and patient education should be conducted regarding these as well.

The study shows that $86.3 \%$ of the mothers consider breast cancer as a life threatening disease and $81.7 \%$ of them were aware that this cancer if detected earlier can be treated. Both these findings are important for this study. This level of awareness is comparable to the study on Polish women as $84 \%$ of them perceived breast cancer a major threat to women. ${ }^{[24]}$ This indicates that women belonging to either the western world or a low socio-economic group of an under developed country such as Pakistan realize that breast cancer is a serious health hazard for women with a high mortality rate but these rates can be decreased with early enough detection

\section{REFERENCES}

[1] Giuliano AE, Hurvitz SA. Current Medical Diagnosis and Treatment, Breast Disorders. Ed. 2012. $702-724$ p.

[2] Shieh SH, Chen HC, Tsai WC. Impact of breast cancer patients' awareness on attendance at screening. International Nursing Review. 2012; 59(3): 353-361. PMid: 22897186. https ://doi.org/10.1 $111 / \mathrm{j} .1466-7657.2012 .00983 . \mathrm{x}$

[3] Shalini, Varghese D, Nayak M. Awareness and Impact of Education on Breast Self Examination Among College Going Girls. Indian Journal of Palliative Care. 2011; 17(2): 150. PMid: 21976857. https://doi.org/10.4103/0973-1075.84538

[4] Shetty MK. Screening and diagnosis of breast cancer in low-resource countries: what is state of the art? Semin Ultrasound CT MR. 2011 Aug; 32(4): 300-5. PMid: 21782120. https ://doi.org/10.105 $3 / j$.sult. 2011.04.002

[5] Kanaga KC, Nithiya J, Shatirah MF. Awareness of breast cancer and screening procedures among Malaysian women. Asian Pac J Cancer Prev. 2011; 12(8): 1965-7. PMid: 22292634.

[6] Han Y, Williams RD, Harrison RA. Breast cancer screening knowledge, attitudes, and practices among Korean American women. Oncol Nurs Forum. 2000 Nov-Dec; 27(10): 1585-91. PMid: 11103377. and management.

The limitations of the study are that it does not take into account the women who have never conceived a child, women taking hormonal replacement therapy and women belonging to high socioeconomic group. Due to these limitations the findings of the study cannot be generalized to the entire population of Pakistan. Also, the subject responses might have been be limited due to the nature of the yes/no questions which can be avoided by designing a questionnaire in future with more open options allowing the study participants to respond more openly.

\section{Conclusions}

The study concludes that though most of the mothers in Karachi have an overall idea about what breast cancer is, there are still several pitfalls that need to be worked on. Especially generation of awareness and educational programs and activities for the women should be undertaken. For this purpose media can play a sufficient role in improving the level of awareness. Also, women should be educated against being shy to see medical care for breast diseases as an earlier and timely diagnosis is the key to a better prognosis. At the same time facilities should be established to make the screening methods and good physicians available to women belonging to low socioeconomic group in a cost effective manner.

\section{CONFLicts OF InTEREST Disclosure}

The authors declare they have no conflict of interest.
[7] Al-Naggar RA, Bobryshev YV, Al-Jashamy K. Practice of breast self-examination among women in Malaysia. Asian Pac J Cancer Prev. 2012; 13(8): 3829-33. PMid: 23098479. https ://doi .org/ 10.7314/APJCP. 2012.13.8.3829

[8] Phillips JM, Cohen MZ, Moses G. Breast cancer screening and African American women: fear, fatalism, and silence. Oncology Nursing Forum. 1999; 26(3): 561-571. PMid: 10214597.

[9] Maqsood B, Zeeshan MM, Rehman F, et al. Breast cancer screening practices and awareness in women admitted to a tertiary care hospital of Lahore, Pakistan. Journal of the Pakistan Medical Association. 2009; 59(6): 418-421. PMid: 19534385.

[10] Benjamin O, Anderson MD, Susan Braun MA, et al. Early Detection of Breast Cancer in Countries with Limited Resources. The Breast Journal. 2003; 9(Suppl s2): S51-S59. https://doi .org/10.104 6/j.1524-4741.9.s2.4.x

[11] Smith P, Hum S, Kakzanov V, et al. Physicians' attitudes and behaviour toward screening mammography in women 40 to 49 years of age. Can Fam Physician. 2012 Sep; 58(9): e508-13. PMid: 22972742.

[12] Madanat H, Merrill RM. Breast cancer risk-factor and screening awareness among women nurses and teachers in Amman, Jor- 
dan. Cancer Nursing. 2002; 25(4): 276. PMid: 12181496. https:

//doi.org/10.1097/00002820-200208000-00003

[13] Dawne MH, Jane EM, Diane MD. Racial differences in breast cancer screening, knowledge and compliance. J Natl Med Assoc. 2003 August; 95(8): 693-701.

[14] Mittra I. Breast cancer screening in developing countries. Prev Med. 2011 Sep; 53(3): 121-2. PMid: 21712052. https ://doi.org/10 $.1016 / \mathrm{j}$.ypmed.2011.06.010

[15] McMenamin M, Barry H, Lennon A. A survey of breast cancer awareness and knowledge in a Western population: lots of light but little illumination. European Journal of Cancer. 2005; 41(3): 393-397. PMid: 15691638. https://doi.org/10.1016/j.ejca.2004.11.015

[16] Kelsey JL, Gammon MD, John EM. Reproductive factors and breast cancer. Epidemiol Rev. 1993; 15(1): 36-47. PMid: 8405211. https: //doi.org/10.1093/oxfordjournals.epirev.a036115

[17] Mccaul KD, Branstetter AD, Schroeder DM, et al. What is the relationship between breast cancer risk and mammography screening? A meta-analytic review. Health Psychology Official Journal of the Division of Health Psychology American Psychological Association. 1996; 15(6): 423-429. https://doi.org/10.1037/0278-6133. 15.6 .423

[18] Vogel VG, Graves DS, Vernon SW, et al. Mammographic screening of women with increased risk of breast cancer. Cancer. 1990;
66(7): 1613. https://doi.org/10.1002/1097-0142(199010 01) $66: 7<1613:$ : AID-CNCR2820660728>3.0.CO;2-E

[19] Taha H, Al-Qutob R, Nyström L, et al. "Voices of fear and safety" women's ambivalence towards breast cancer and breast health: a qualitative study from Jordan. BMC Womens Health. 2012 Jul 26; 12: 21. d https://doi.org/10.1186/1472-6874-12-21

[20] Katapodi MC, Lee KA, Facione NC, et al. Predictors of perceived breast cancer risk and the relation between perceived risk and breast cancer screening: a meta-analytic review. Preventive Medicine. 2004; 38(4): 388-402. PMid: 15020172. https://doi.org/10.1016/j. ypmed.2003.11.012

[21] Parameshwari P, Muthukumar K, Jennifer HG. Study on breast cancer and associated risk factors. J Clin Diagn Res. 2013 Sep; 7(9): 1913-6. PMid: 24179896.

[22] Abali H, Ata A, Gokce G. Possible logistic and sociodemographic factors on breast cancer screening in Turkey. Journal of Cancer Education. 2012; 27(2): 347-352. PMid: 21976034. https://doi.or $\mathrm{g} / 10.1007 / \mathrm{s} 13187-011-0270-7$

[23] Olubenga-Bello A, Oladele EA, Bello TO. Awareness and breast cancer risk factors perception and screening practices in Southwest Nigeria. Niger Postgrad Med J. 2011 March; 18(1): 8-15.

[24] Najdhyor E, Krajewska-Kulak E, Krajewska-Ferishah K. Knowledge of women and men about breast cancer prevention. Ginekol Pol. 2013 Feb; 84(2): 116-2. 